\title{
Nematic Mesogen with 1,3,4-Oxadiazole Unit as Stationary Phase in Gas-Liquid Chromatography
}

\author{
Zainab Jasim and Nasreen R. Jber*
}

Department of Chemistry, College of Science, Al-Nahrain University, Baghdad-Iraq

\begin{tabular}{ll}
\hline \multicolumn{1}{c}{ Article's Information } & \multicolumn{1}{c}{ Abstract } \\
\hline Received: & This paper is the first that deals with the new synthesis of nematic liquid crystal \\
12.08 .2021 & titled bis-[5-yl-phenylbenzidine-4-butyloxyphenly-2-yl-1,3,4-oxadiazole] and \\
Accepted: & secondly discusses research on materials that can be used in stationary phase by \\
13.09 .2021 & using (GLC) as a type of chromatography. The usage of bis-[5-yl-phenylbenzidine- \\
Published: & 4 -butyloxyphenly-2-yl-1,3,4-oxadiazole] nematic phase has resulted in a lot of \\
30.09 .2021 & superb separations of a lot of poly aromatic hydrocarbons. The retention time \\
Keywords: & change in an unusual way with temperature, appearance a significant increase at \\
Liquid crystals & the normal liquid transmission point; as expected, that impact is reduced with \\
1,3,4-Oxadiazole & further planar compounds. FT-IR and ${ }^{-H N M R}$ were used to characterize the \\
Gas chromatography & synthesized chemical structure, and POM and DSC were used to investigate the \\
Stationary phase & liquid crystalline characteristics.
\end{tabular}

DOI: $10.22401 /$ ANJS.24.3.05

*Corresponding author: Nasreen.jber@ced.nahrainuniv.edu.iq

\section{Introduction}

The situation of materials known as liquid crystals that exist amid crystalline solids and isotropic liquids that are "normal", but is surprisingly underappreciated. Certain elongated compounds, moderately molecules that are polar create them, and their reverse attraction causes its lengthy axes to align [1]. An anisotropic liquid is formed when these materials dissolve, which only allows molecules to motion freely as long they are staying in parallel to each other, when the temperature is high, its melt transitions to the conventional liquid. Appointed compounds not only one phase but contain two distinguished liquid crystal phases. These are melting produce the smectic phase where the molecule is not only confined for being parallel. However, they are organized as layers, when the temperature is high, this extra constraint is lost, and nematic phases transitions to the regular liquid, at high temperature, nematic phase convert to the true liquid [2].

As a result, LCs acting mechanical like liquids while retaining several of its ordering of crystalline linear solids. Solute molecules should be expected to just be orientated in parallel to it the solvent molecule if a substance with rodshaped molecules dissolvable under the liquid crystal. Physical and chemical consequence of the associated geometrical limitation should be apparent and interesting, and crystalline liquid must exhibit quite unusual characteristics of the solvent [3].

Using gas-liquid chromatography, LCs are utilizing for stationary phases. On a particular column, relative retention durations in a variety of samples are mostly influenced by theirs. Coefficients of partition in between liquid and gaseous phases: are determined firstly by sample's boiling point, secondly by, plus then by particular interaction in between molecules and ones of the liquid crystalline phase second [4]. As a result, existing column packings distinguish themselves primarily by point of boiling and for in a situation involving packagings, by unique interactions of solute and solvents. As a result, separating positional isomers with minor polarity differences might be challenging. $\mathrm{p}$ - and m-xylene constitutes a style technically substantial example. LCs could be the best way to overcome this stalemate, as have respective affinities to a string of the isomers are thought into influenced by other configurations. Furthermore, one could anticipate optical active liquid crystalline to give the way of analysis dl-mixtures using GLC, that challenge that has so far remained unaddressed.

Environmental research in a variety of disciplines relies on the composition of complicated hydrocarbon mixtures. However, standard gas chromatography (GC) technologies cannot reliably identify many common chemicals. The growing demand for isomeric compound studies, as well as the difficulties faced in their separation, necessitates the development of more efficient methods with excellent selectivity. In GC, nematic of liquid crystals were originally employed a stereospecific stationary phase by Kelker and Fresenius [5]. Using stationary phases for their separate of those isomers with identical volatilities, the nematic liquid crystal had demonstrated this sensitivity and special selectivity, Due to their distinct preference for stiff solute isomers. At one-point, liquid crystal stationary phases were 


\section{Al-Nahrain Journal of Science}

ANJS, Vol.24 (3), September, 2021, pp. 30-37

rate to represent a particularly promising family of materials, that can produce considerably distinct gas chromatographic separations than every stationary phase. Ever since its separation characteristics of this diverse collection of compounds have received a lot of attention. LC may be utilized to separate a wide range of these substances, involve isomer combinations that are impossible to separate with traditional stationary phases. This work intends to offer is comparable analysis research of monomeric of nematics liquid crystal as stationary phases utilized in gas chromatography, as well as revise all particular empirical data.

\section{Instrumental}

Both chemicals and solvents were of annular grade. They were used without any further purification. With samples embedded in $\mathrm{KBr}$ pellets, FT-IR data were collected with a Shimadzu 8300 Fourier Transform Infrared spectrophotometer in the frequency range of 4000 to $400 \mathrm{~cm}^{-1}$. A Bruker $500 \mathrm{MHz}$ NMR Spectrometer was used to capture ${ }^{1} \mathrm{HNMR}$ spectra in DMSO, with trimethylsilane (TMS) serving as the internal standard. POM studied the liquid crystalline properties with a (Meiji MT9000) Polarizing

\begin{abstract}
Optical Microscope connected to an INSTEC Hot point. Polarized light with crossed polarizers was used to examine the texture of the compounds, preparing the sample as a thin film sandwiched in between a glass slide and a cover. Upon on polarizing microscope, a camera (Lumenera) was installed. A LINSEIS DSC PT-1000 differential scanning calorimeter was used to test the transition temperatures and enthalpies, which were calibrated with indium $\left(156.6{ }^{\circ} \mathrm{C}\right.$, $28.45 \mathrm{~J} / \mathrm{g}$ ) and a heating rate of $10.0^{\circ} \mathrm{C} / \mathrm{min}$. in air. A flame ionization detector is included in the Shimadzu GC-9A gas chromatography (FID) The system was connected to the data controller (Shimadzu C-R6A) that could plot a chromatogram and print information by the same registration thermal chart sheet. for carrier gas, high-quality nitrogen gas (99.99 percent) had employed. The soap bubble flow-meter was used to scale its flow-rate. The temperature of an FID \& injector was kept as 240 degrees Celsius. samples ranging from 0.5 to $1.0 \mu \mathrm{L}$ are as an injection in a column.
\end{abstract}

\section{Synthesis}

The intermediary compounds were synthesized as to the following Schema 1:

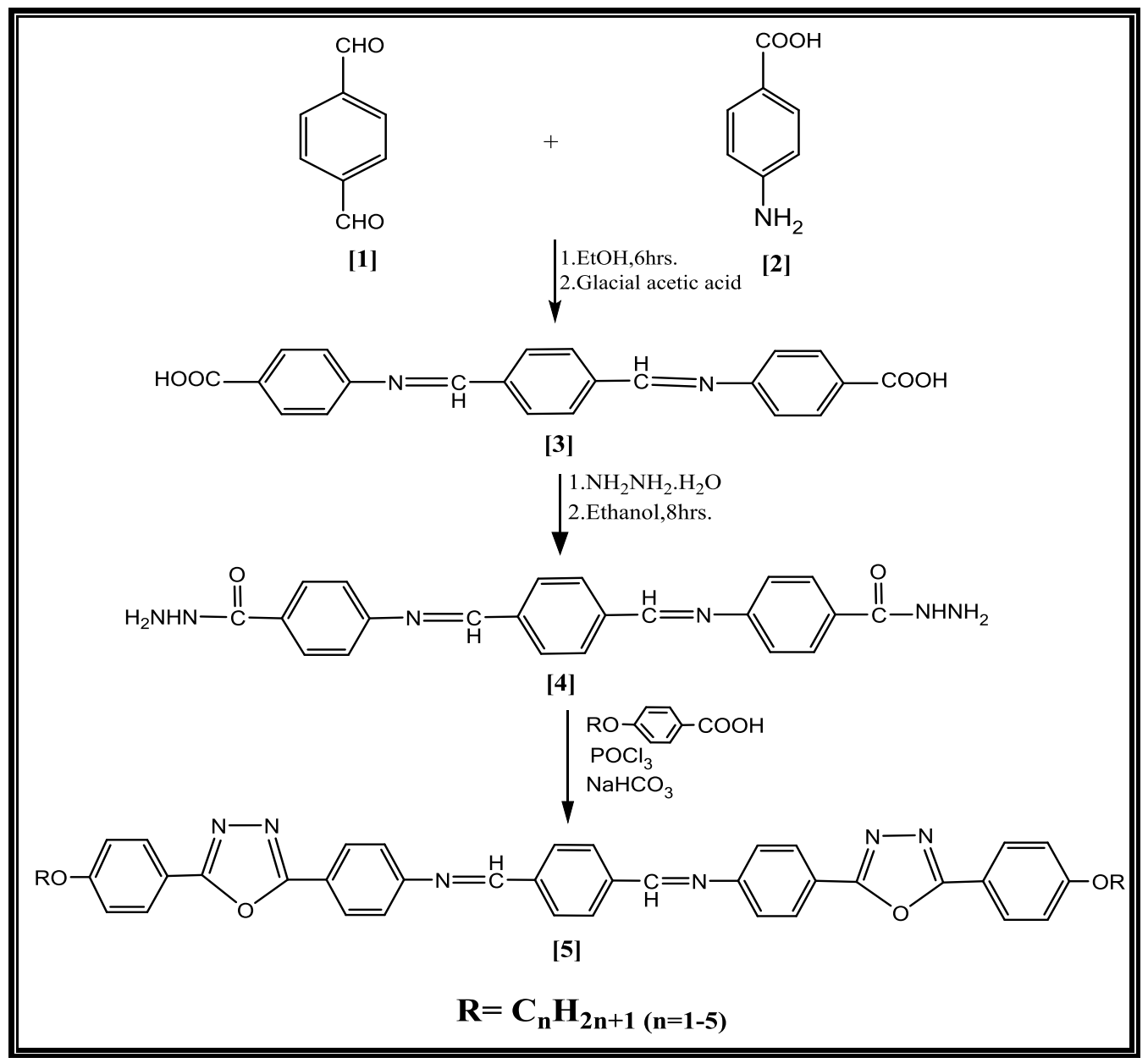

Scheme 1. The path of synthesis compounds. 


\section{Al-Nahrain Journal of Science}

ANJS, Vol.24 (3), September, 2021, pp. 30-37

\section{Preparation P-Alkoxy benzoic acid [6]}

The p-hydroxybenzoic acid ( $5 \mathrm{~g}, 0.03$ mole) dissolved in 20 $\mathrm{ml}$ (ethanol) (5.1 gm, 0.09 mole) by stirring, then added $\mathrm{KOH}$, and A mixture allowed to cool to room temperature. Appropriate alkyl bromide ( 0.165 moles $)$ has been applied dropwise. The solution has been refluxed overnight, (1.12 gm, mole 0.02) $\mathrm{KOH}$ been put into the mixture, dissolved in a tiny amount of water $(\sim 5 \mathrm{ml})$, then refluxed for (1-3) hrs. The HCL was added to the solution, Conc $\mathrm{HCl}$ acidification yielded a white 4-alkoxybenzoic acid precipitate. Recrystallization from ethanol gave the desired products. The yield is $80 \%$, m.p. 147-150.

\section{Synthesis of 1,4-phenylenebis (methanylylidene) bis (4-aminobenzoic acid) [3] [7]}

Terephthalaldehyde ( $1.34 \mathrm{~g}, 0.01$ mole) was added in 20 $\mathrm{mL}$ of ethanol in around bottomed flask with three drops of G.acetic acid is a catalyst and stir without heat until it dissolves completely. Then add 4-aminobenzoic acid (2.74 $\mathrm{g}, 0.01 \mathrm{~mole})$, and refluxed the mixture for $(6 \mathrm{~h})$. Then cooled the resultant solution to room temperature. The resulting light-yellow solid crystal where it had been filtering then recrystallized of appropriate solvent (ethanol) to obtain the compound [3]. The yield is 60\%, m.p. 220-225.

\section{Synthesis of 4,4-\{benzene-1,4-diyl bis [(E) methylylidene (E) azanylylidene]\}- \\ dibenzohydrazide [4] [8]}

( $3.72 \mathrm{~g}, 0.01 \mathrm{~mole}$ ) of compound (3) was added to $15 \mathrm{ml}$ of Hydrazine hydrate in the bottomed flask and refluxed the mixture for $(4 \mathrm{~h})$ overnight, then added ethanol $(15 \mathrm{~mL})$ and 4 hours of reflux. The resulting solution allowed to cool to room temperature, resulting in an oily compound [4]. Yield $62 \%$.

\section{Synthesis of compound (1E)-N-(4-[5-(4-alkoxy phenyl)-1,3,4-oxadiazol-2-yl)phenyl)-1-[4-(4-(5-(4- alkoxy phenyl)-1,3,4-oxadiazol-2-yl-phenyl-imino- methyl phenyl methanimine [5] $]_{\mathrm{d}}[9]$}

Compound A2, $(0.01 \mathrm{~mol})$ and $(0.02 \mathrm{~mol})$ of P-butoxy benzoic acid with $10 \mathrm{ml} \mathrm{POCl}_{3}$ were refluxed to 24 hours. cold mixture was casted on crush ice then made basic by adding $\mathrm{NaHCO}_{3}$, solution. The solid that resulted has been filtering, then dry to give oxadiazole with yield $70 \%$, m.p. (202-208).

\section{Preparation of compound N,N-Terephthalylidene-} bis-4- butyl aniline [A], [10]

This compound was prepared as shown in the following Scheme 2.

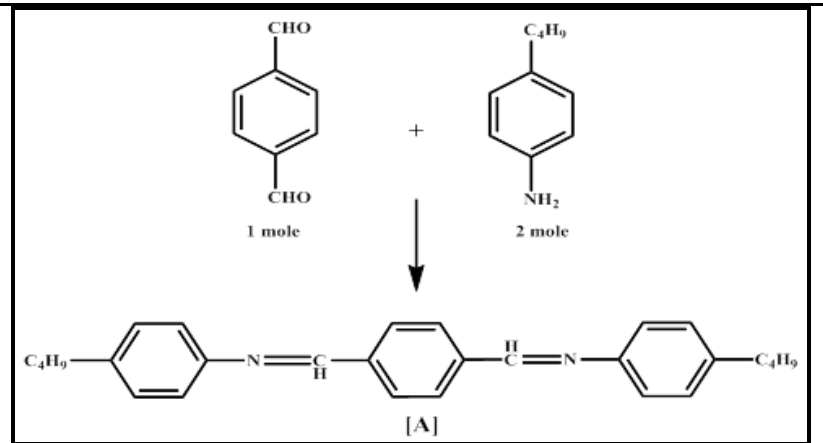

Scheme 2. Synthesis of N,N-Terephthalylidene-bis-4-butyl aniline.

Terephthaldehyde ( $1.34 \mathrm{~g}, 0.01$ mole) was added in 20 $\mathrm{mL}$ of ethanol with three drops of glacial.acetic acid then added 4-butyl aniline ( 0.02 mole, $3.15 \mathrm{ml})$ and refluxed the mixture for $(4 \mathrm{hrs}$.). Cooled the resultant solution to room temperature, and it was filtered to prepare it for the stationary phase. Yield $60 \%$, m.p. 232-233.

\section{Synthesis and Characterization}

The compound $[5]_{\mathrm{d}}$ was diagnosed using the technique FTIR as follows: the disappearance of amino hydrazide group as well as the appearance of stretching bands made up of new aliphatic compounds. The spectra of these compounds show characteristic bands for arom. $\mathrm{C}-\mathrm{H}$ in the range (3057) $\mathrm{cm}^{-1}$, bands for aliphatic $\mathrm{C}-\mathrm{H}$ in the range (2961) $\mathrm{cm}^{-1}$ for asymmetrical stretching and (2874) $\mathrm{cm}-1$ for symmetrical stretching, the spectra also show bands in the range $(1631) \mathrm{cm}-1$ for $\mathrm{CH}=\mathrm{N}$ of imine group. Other bands at (1605.7), (1251), (842) $\mathrm{cm}^{-1}$ may be attributed to $\mathrm{C}=\mathrm{C}$, $\mathrm{C}-\mathrm{O}$, and out of plane bending of para- disubstituted benzene. The typical absorption bands in FTIR spectroscopy are shown in Figure 1.

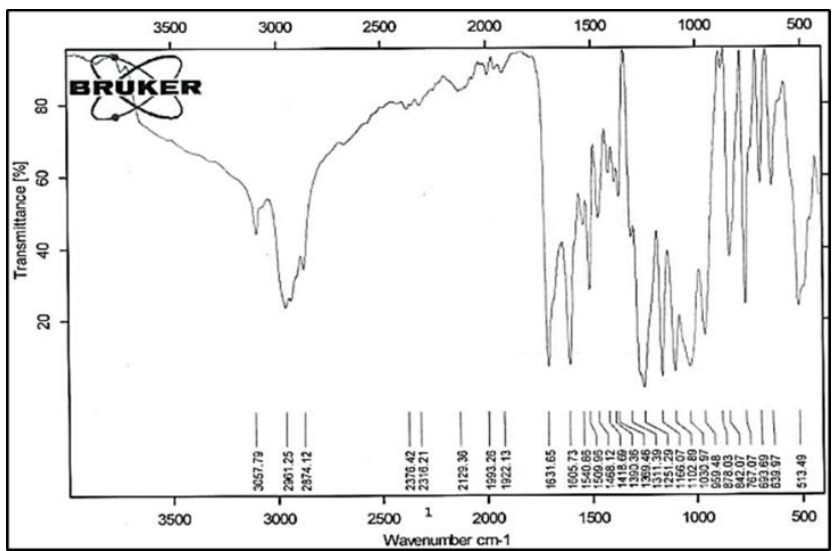

Figure 1. FTIR spectrum of compounds $[5]_{\mathrm{d}}$.

${ }^{1} \mathrm{HNMR}$ spectroscopy was used to confirm the structure of this series. Figure 2 shows the $1 \mathrm{H}-\mathrm{NMR}$ spectrum of compound $[5]_{\mathrm{d}}$, the following characteristic chemical shifts (d6-DMSO, ppm) were appeared: signal at d 8.57-8.58 ppm could be assigned to the proton of imine group $\mathrm{CH}=\mathrm{N}(2 \mathrm{H})$, the aromatic protons show three signals at $\mathrm{d} 6.52-8.17$ $(20 \mathrm{H})$. Butoxy group appears as $(4 \mathrm{H})$ triplet at d $3.8 \mathrm{ppm}$, 


\section{Al-Nahrain Journal of Science}

ANJS, Vol.24 (3), September, 2021, pp. 30-37

(8H) multiplet at d $1.7-2.0 \mathrm{ppm},(6 \mathrm{H})$ triplet at $\mathrm{d} 1.0$, for $-\mathrm{OCH}_{2},-\mathrm{CH}_{2} \mathrm{CH}_{2}-,-\mathrm{CH}_{3}$, respectively.

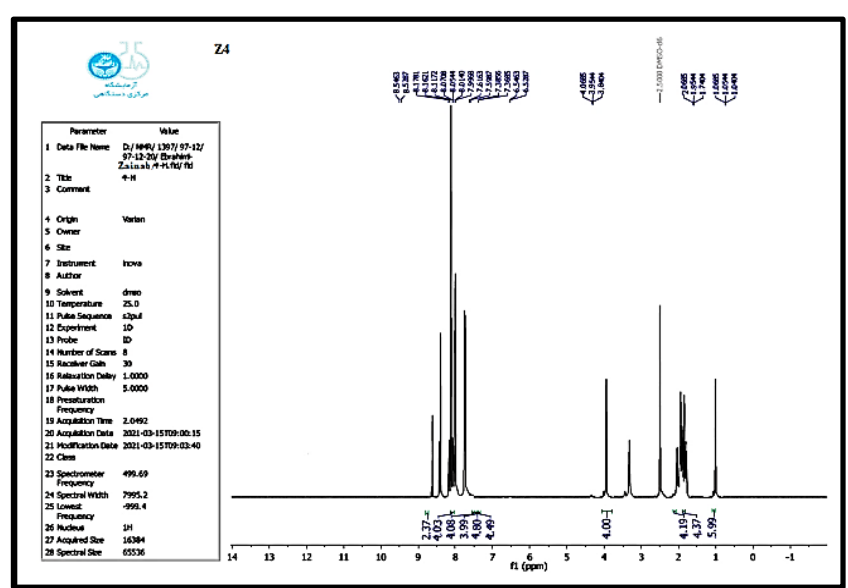

Figure 2. ${ }^{1} \mathrm{HNMR}$ spectrum of compound $[5]_{\mathrm{d}}$.

Figure 3 showed the characteristic absorption bands in FTIR spectroscopy for compound [A]: The spectra of this compound show characteristic band for aromatic $\mathrm{C}-\mathrm{H}$ in the range $(3021) \mathrm{cm}^{-1}$, bands for aliphatic $\mathrm{C}-\mathrm{H}$ in the range (2956) $\mathrm{cm}^{-1}$ for asymmetrical stretching, and (2853) $\mathrm{cm}^{-1}$ for symmetrical stretching, bands at $1557,1617,831 \mathrm{~cm}^{-1}$ that could be attributed to $\mathrm{C}=\mathrm{C}, \mathrm{CH}=\mathrm{N}$, and out of plane bending of para-disubstituted benzene.

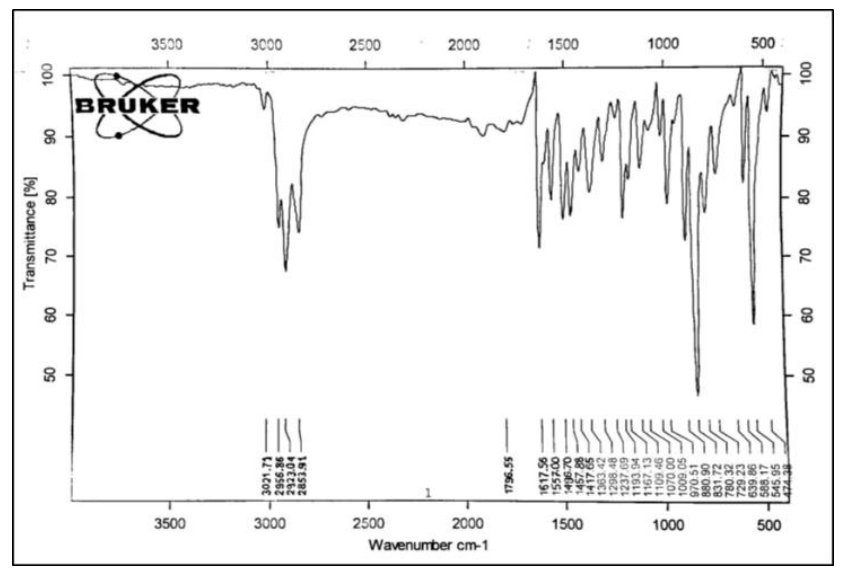

Figure 3. FTIR spectrum of compounds [A].

The liquid crystalline property was determined using a Differential scanning thermogram and gave a heat transfer in the range (201-214), as shown in Figure 4.

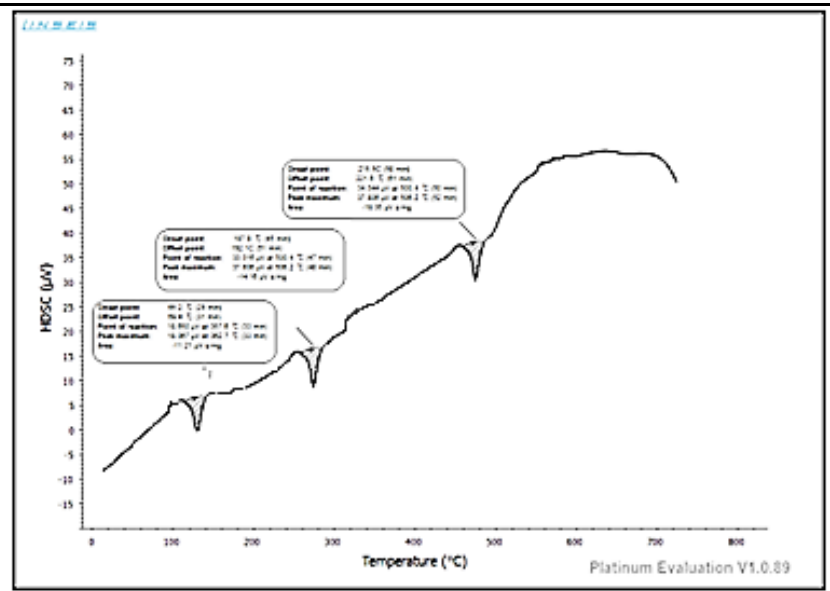

Figure 4. Differential scanning thermogram of compound $[5]_{\mathrm{d}}$.

Polarized optical microscopy used to determine the nematic phase in the form of Droplet-shape, as shown in Figure 5.

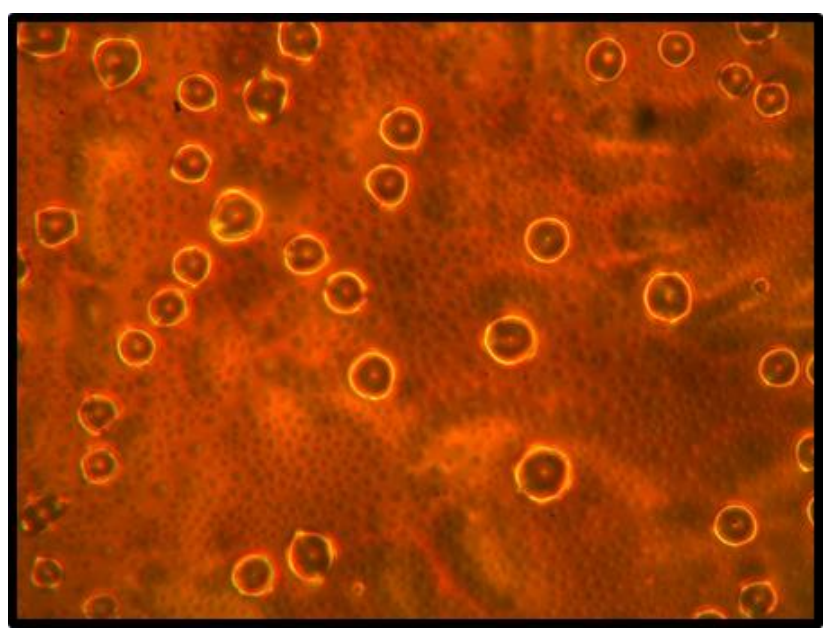

Figure 5. Nematic phase of compounds [5] $]_{\mathrm{d}}$ (magnification $10 \times 10$ ).

\section{Preparation stationary phase [11]}

All liquid crystal substances are coated on chromosorb W/AW 60 - 80 mesh size to create stationary phases, solid support. Various liquid crystal compound weights ( $2 \mathrm{~g}$ ) with solid support weights $(8 \mathrm{~g})$ have been utilized for the preparation of a stationary liquid crystal process with a coating percentage of 20 percent. Liquid crystal compounds are first dissolved in $50 \mathrm{~mL}$ of chloroform, then slowly applied to the solution by stirring to form a slurry. Including full uniform and homogeneous covering of liquid crystal onto solid support particles, the stirring was continued for 72 hours. A rotary evaporator was then used to evaporate the solvent, after that, the stationary phase was dried for (2 hrs.) at $100{ }^{\circ} \mathrm{C}$. 


\section{Al-Nahrain Journal of Science}

ANJS, Vol.24 (3), September, 2021, pp. 30-37

\section{Packing and Conditioning Process [12]}

The liquid crystal stationary phases were filled into the Pyrex glassy column at a rate of $20 \%$ (loading percent). The packaging process methodology is listed below.

At one end of the column, a piece of glass wool was inserted, It was connected to a vacuum pump in this area. On the other end, a plastic funnel was attached. After the prepared stationary phases have dried, added out of the funnel to the column to ensure a full also in addition to the vacuum pump, there is a consistent packing system, the vibration was used. Porosity in stationary phase particles would be reduced, as well as the column's dead spaces would be eliminated Following the finishing of the packing procedure, after that, it was also glam wool added. on the other side of the column columns that were prepared were initialization as follows: The temperature of the column was held between 10 -15 degrees celsius above the highest temperature at which the column was applied, with a nitrogen gas stream flowing through the column.

The column was held in these conditions for 48 hours. It was important to condition the column extract the residual solvent, Any other volatiles, also humidity. The column was also weighed before and after packing to ensure that the stationary phase is not lost and that the packing is complete and consistent. By increase the temperature of the column by 10 or 20 degrees Celsius to cover the entire transition temperature ranges of the particular liquid crystal between each run, all of the fixed phases were checked separately. Direct injection of $1 \mathrm{pl}$ of each sample into the device was used, with a $20 \mathrm{~mL} / \mathrm{min}$ flow rate. The flow rate of the carrier gas was calculated using a soap-bubble flow meter, by attaching it to the detector's outlet.

\section{Results and Discussion}

A gas-liquid chromatography (GLC) test was performed using a Pye Unicam GLC system. Nitrogen has been used as a mobile phase, as well as flame ionization detector were used. column packaging included $20 \mathrm{wt} \%$ of the solid supporting fluid crystal stationary phase Chromosorb W. (60-80 mesh). The column was stagnant liquid for 24 hours before usage started at $15^{\circ} \mathrm{C}$ the crystal phase of the nematic isotropic (N-I) transition through temperature. Table 1 shows the stationary phase of the liquid crystal utilized in this study.

Table 1. The crystalline liquid stationary phases.

\begin{tabular}{|c|c|c|c||}
\hline \hline Stationary phases & M.Wt & Name of the compound and its chemical formula & Max. analysis Temp. ${ }^{\circ} \mathrm{C}$ \\
\hline \hline$[\mathrm{A}]$ & 397 & 232 \\
\hline$[5]_{\mathrm{d}}$ & 717 & $\begin{array}{l}\left(\mathrm{HO}-\mathrm{CH}_{2} \mathrm{CH}_{2} \mathrm{O}\right)_{\mathrm{n}}-\mathrm{H} \\
\text { Polyethylene glycol }\end{array}$ & 255 \\
\hline $\mathrm{PEG}$ & 6000 & \\
\hline
\end{tabular}

The analysis of polyaromatic hydrocarbon $(\mathrm{PAH})$ at $20 \%$ of the aforementioned liquid crystal column, phenanthrene, naphthalene, anthracene and fluorene were tested. The mesophase transitioning range was used to measure its retention time for every component in the mixes. $100-230^{\circ} \mathrm{C}$.

Figure 6 represents the analysis of (PAH) mixture using $\mathrm{N}, \mathrm{N}-\mathrm{Terephthalylidene-bis-4-butyl}$ aniline[A], whereas figure (7) shows the separation using N-(4-[5-(4-alkoxy phenyl)-1,3,4-oxadiazol-2-yl) phenyl)-1-[4-(4-(5-(4-alkoxy phenyl)-1,3,4-oxadiazol-2-yl-phenyl-imino-methyl phenyl methanimine $[4 \mathrm{~d}]$ as stationary phase. The statistics for the duration of retention are given in Tables 2 and 3. The mixture was separated in column $20 \%$ PEG in order to compare the separation in the standard column, and there was no separation under similar conditions.

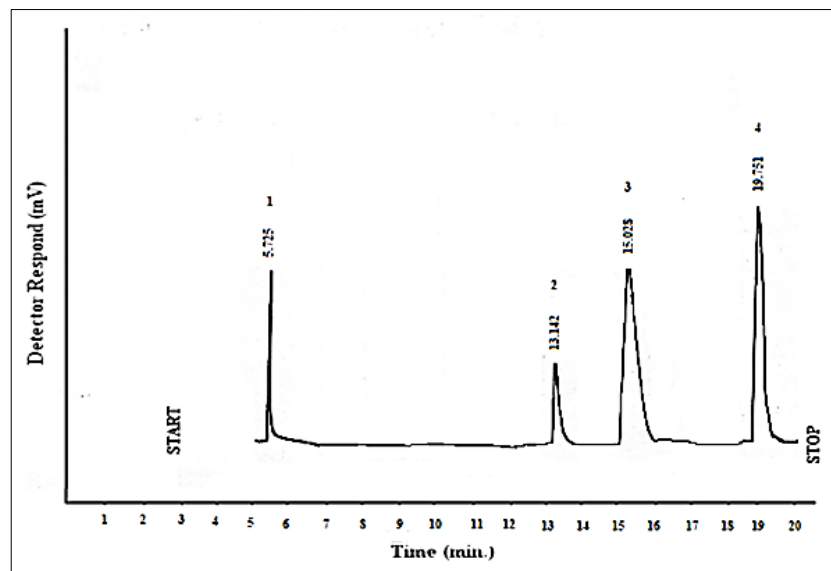

Figure 6. Chromatogram of fused ring PAH hydrocarbones of N,N-Terephthalylidene-bis-4- butyl aniline[A] Condition oven temperature $160{ }^{\circ} \mathrm{C}$; Fc $25 \mathrm{ml} / \mathrm{min}$ and detector temperature $200{ }^{\circ} \mathrm{C}$, peak: naphtalene 1, fluorene 2, phenanthrene 3 and anthracene 4 . 


\section{Al-Nahrain Journal of Science}

ANJS, Vol.24 (3), September, 2021, pp. 30-37

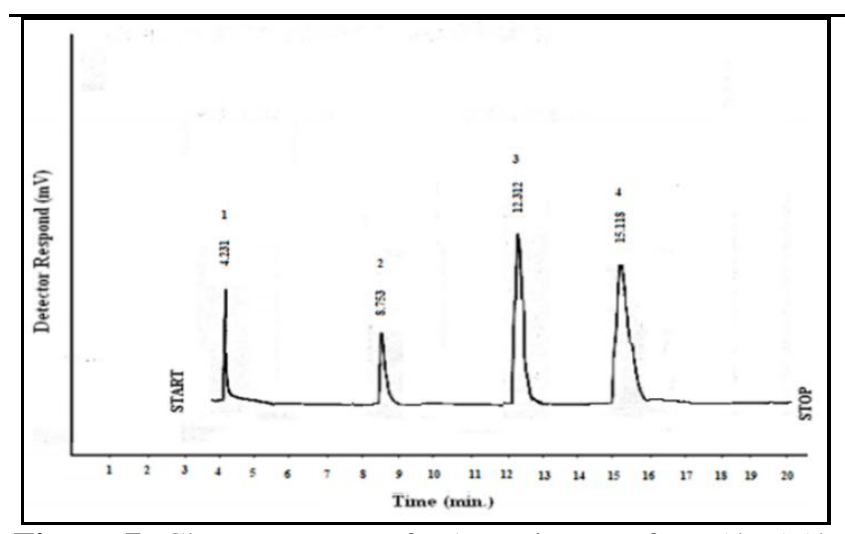

Whenever the order of fluid crystal steady phase greater made it simpler to hold material molecules remain inside the column and get stronger longer, so was preferable separation at $200{ }^{\circ} \mathrm{C}$. As the temperature rises, the period of retention decreases as the liquid crystal order diminishes.

Figure 7. Chromatogram of PAH mixture of $\mathrm{N}$-(4-[5-(4alkoxy phenyl)-1,3,4-oxadiazol-2-yl)phenyl)-1-[4-(4-(5-(4alkoxy phenyl)-1,3,4-oxadiazol-2-yl-phenyl-imino-methyl phenyl methanimine [4d] Condition oven temperature 160 ${ }^{\circ} \mathrm{C}$; Fc $25 \mathrm{ml} / \mathrm{min}$ and detector temperature $200{ }^{\circ} \mathrm{C}$, peak: naphtalene 1 , fluorene 2 , phenanthrene 3 and anthracene 4.

Table 2. Adjusted retention times (t'R / minute) for PAH mixture on 20\% N,N-Terephthalylidene-bis-4- butyl aniline [A].

\begin{tabular}{||c|c|c|c|c||}
\hline \multicolumn{2}{|c|}{ Retention Time (t's $/$ min.) } \\
\hline Temp. ${ }^{\circ} \mathbf{C}$ & Fluorene & Phenanthrene & \multirow{2}{*}{ Anthracene } \\
\hline \hline $100^{\circ} \mathrm{C}$ & Naphthalene & 14.401 & 16.409 & 20.658 \\
\hline $110^{\circ} \mathrm{C}$ & 5.828 & 14.042 & 16.057 & 20.196 \\
\hline $120^{\circ} \mathrm{C}$ & 5.682 & 13.974 & 15.892 & 19.872 \\
\hline $130^{\circ} \mathrm{C}$ & 5.385 & 13.847 & 15.700 & 19.594 \\
\hline $140^{\circ} \mathrm{C}$ & 5.174 & 13.788 & 15.271 & 19.139 \\
\hline $150^{\circ} \mathrm{C}$ & 4.943 & 13.632 & 14.938 & 18.778 \\
\hline $160^{\circ} \mathrm{C}$ & 4.702 & 13.576 & 14.103 & 18.503 \\
\hline $170^{\circ} \mathrm{C}$ & 4.655 & 13.183 & 13.668 & 18.228 \\
\hline $180^{\circ} \mathrm{C}$ & 4.501 & 12.948 & 13.056 & 17.814 \\
\hline $190^{\circ} \mathrm{C}$ & 4.221 & 12.801 & 12.812 & 17.347 \\
\hline $200^{\circ} \mathrm{C}$ & 4.024 & 12.628 & 12.635 & 16.852 \\
\hline $210^{\circ} \mathrm{C}$ & 3.980 & 12.328 & 12.128 & 16.748 \\
\hline
\end{tabular}

Table 3. Adjusted retention times (t'R / minute) for PAH mixture on 20\% N-(4-[5-(4-alkoxy phenyl)-1,3,4-oxadiazol-2-yl) phenyl)-1-[4-(4-(5-(4-alkoxy phenyl)-1,3,4-oxadiazol-2-yl-phenyl-imino-methyl phenyl methanimine [5] $]_{\mathrm{d}}$.

\begin{tabular}{|c|c|c|c|c|}
\hline \multicolumn{5}{|c|}{ Retention Time (t's /min.) } \\
\hline Temp. ${ }^{\circ} \mathrm{C}$ & Naphthalene & Fluorene & Phenanthrene & Anthracene \\
\hline $100^{\circ} \mathrm{C}$ & 5.528 & 9.471 & 13.428 & 16.898 \\
\hline $110^{\circ} \mathrm{C}$ & 5.186 & 9.042 & 13.156 & 16.146 \\
\hline $120^{\circ} \mathrm{C}$ & 4.915 & 8.613 & 12.992 & 15.872 \\
\hline $130^{\circ} \mathrm{C}$ & 4.648 & 8.247 & 12.724 & 15.694 \\
\hline $140^{\circ} \mathrm{C}$ & 4.449 & 8.088 & 12.440 & 15.039 \\
\hline $150^{\circ} \mathrm{C}$ & 4.301 & 7.954 & 12.138 & 14.978 \\
\hline $160^{\circ} \mathrm{C}$ & 4.089 & 7.705 & 11.853 & 14.793 \\
\hline $170^{\circ} \mathrm{C}$ & 3.846 & 7.453 & 11.660 & 14.568 \\
\hline $180^{\circ} \mathrm{C}$ & 3.429 & 7.048 & 11.249 & 14.314 \\
\hline $190^{\circ} \mathrm{C}$ & 3.125 & 6.985 & 11.054 & 14.024 \\
\hline $200^{\circ} \mathrm{C}$ & 2.887 & 6.541 & 10.985 & 13.514 \\
\hline $210^{\circ} \mathrm{C}$ & 2.597 & 6.248 & 11.583 & 13.224 \\
\hline
\end{tabular}




\section{Al-Nahrain Journal of Science}

ANJS, Vol.24 (3), September, 2021, pp. 30-37

At $200{ }^{\circ} \mathrm{C}$, the highest selectivity factors were achieved. This has been ascribed to the optimal structural configuration system of the nematic lattice layer. For each neighboring peak, the selectivity factor has been computed. The selectivity factor values for PAH mixture are shown in Tables 4 and 5.

Table 4. Selectivity factor $(\alpha)$ for PAH mixture on $[\mathrm{A}]$.

\begin{tabular}{|c|c|c|c||}
\hline \multicolumn{4}{|c|}{ Selectivity factor $\boldsymbol{\alpha}$} \\
\hline \hline $100^{\circ} \mathrm{C}$ & 1.23 & 1.34 & 1.09 \\
\hline $110^{\circ} \mathrm{C}$ & 1.19 & 1.33 & 1.10 \\
\hline $120^{\circ} \mathrm{C}$ & 1.24 & 1.35 & 1.11 \\
\hline $130^{\circ} \mathrm{C}$ & 1.24 & 1.34 & 1.10 \\
\hline $140^{\circ} \mathrm{C}$ & 1.23 & 1.37 & 1.13 \\
\hline $150^{\circ} \mathrm{C}$ & 1.22 & 1.35 & 1.04 \\
\hline $160^{\circ} \mathrm{C}$ & 1.27 & 1.30 & 1.15 \\
\hline $170^{\circ} \mathrm{C}$ & 1.26 & 1.34 & 1.17 \\
\hline $180^{\circ} \mathrm{C}$ & 1.28 & 1.29 & 1.23 \\
\hline $190^{\circ} \mathrm{C}$ & 1.21 & 1.28 & 1.21 \\
\hline $200^{\circ} \mathrm{C}$ & 1.25 & 1.38 & 1.32 \\
\hline $210^{\circ} \mathrm{C}$ & 1.23 & 1.30 & 1.17 \\
\hline
\end{tabular}

Table 5. Selectivity factor $(\alpha)$ for PAH mixture on $[5]_{\mathrm{d}}$. Selectivity factor $\alpha$

\begin{tabular}{|c|c|c|c|}
\hline \multicolumn{4}{|c|}{ Selectivity factor $\alpha$} \\
\hline 10 & Flu. /Naph. & Phen./Flu. & Anth./Phen \\
\hline $100^{\circ} \mathrm{C}$ & 1.23 & 1.24 & 1.09 \\
\hline $110^{\circ} \mathrm{C}$ & 1.19 & 1.23 & 1.10 \\
\hline $120^{\circ} \mathrm{C}$ & 1.24 & 1.25 & 1.11 \\
\hline $130^{\circ} \mathrm{C}$ & 1.24 & 1.24 & 1.10 \\
\hline $140^{\circ} \mathrm{C}$ & 1.23 & 1.27 & 1.13 \\
\hline $150^{\circ} \mathrm{C}$ & 1.22 & 1.35 & 1.04 \\
\hline $160^{\circ} \mathrm{C}$ & 1.27 & 1.30 & 1.15 \\
\hline $170^{\circ} \mathrm{C}$ & 1.26 & 1.34 & 1.17 \\
\hline $180^{\circ} \mathrm{C}$ & 1.28 & 1.29 & 1.18 \\
\hline $190^{\circ} \mathrm{C}$ & 1.28 & 1,28 & 1.17 \\
\hline $200^{\circ} \mathrm{C}$ & 1.35 & 1.38 & 1.20 \\
\hline $210^{\circ} \mathrm{C}$ & 1.28 & 1.30 & 1.11 \\
\hline
\end{tabular}

To assess the effectiveness and performance of the column separation, the effective plate number Neff is needed in the column defined by the following equation [Neff $=16\left(t^{\prime} R / w\right)$ 2] [13] Therefore, the plate number is regarded optimum at a maximum temperature of $120{ }^{\circ} \mathrm{C}$. Tables 6 and 7 show the Neff $4 d$ column value for PAH mixture.

Table 6. The effective plate number (Neff) for PAH mixture on [A].

\begin{tabular}{|c|c|c|c|c|}
\hline \multicolumn{5}{|c|}{ Neff } \\
\hline $\begin{array}{lll} & \text { Comp. } \\
& \text { Temp. }{ }^{\circ} \mathrm{C} & \end{array}$ & Naphthalene & Fluorene & Phenanthrene & Anthracene \\
\hline $100^{\circ} \mathrm{C}$ & 4531 & 1244 & 3808 & 18274 \\
\hline $110^{\circ} \mathrm{C}$ & 5399 & 975 & 2838 & 16682 \\
\hline $120^{\circ} \mathrm{C}$ & 3638 & 1197 & 2254 & 17827 \\
\hline $130^{\circ} \mathrm{C}$ & 3638 & 1197 & 3020 & 17827 \\
\hline $140^{\circ} \mathrm{C}$ & 1907 & 1099 & 2254 & 11142 \\
\hline $150^{\circ} \mathrm{C}$ & 1747 & 750 & 1838 & 10233 \\
\hline $160^{\circ} \mathrm{C}$ & 1258 & 724 & 1635 & 7143 \\
\hline $170^{\circ} \mathrm{C}$ & 3638 & 1197 & 1307 & 17827 \\
\hline $180^{\circ} \mathrm{C}$ & 3638 & 1197 & 1126 & 17827 \\
\hline $190^{\circ} \mathrm{C}$ & 911 & 635 & 2254 & 5086 \\
\hline $200^{\circ} \mathrm{C}$ & 7814 & 1597 & 4922 & 30527 \\
\hline $210^{\circ} \mathrm{C}$ & 653 & 510 & 2254 & 3499 \\
\hline
\end{tabular}




\section{Al-Nahrain Journal of Science}

ANJS, Vol.24 (3), September, 2021, pp. 30-37

Table 7. The effective plate number (Neff) for PAH mixture on [5] $]_{\text {a-e. }}$.

\begin{tabular}{|c|c|c|c|c|}
\hline \multicolumn{5}{|c|}{ Neff } \\
\hline${ }_{\text {Temp. }{ }^{\circ} \mathrm{C}}$ Comp. & Naphthalene & Fluorene & Phenanthrene & Anthracene \\
\hline $100^{\circ} \mathrm{C}$ & 4531 & 1244 & 3808 & 18274 \\
\hline $110^{\circ} \mathrm{C}$ & 5399 & 975 & 2838 & 16682 \\
\hline $120^{\circ} \mathrm{C}$ & 1907 & 1099 & 2254 & 11142 \\
\hline $130^{\circ} \mathrm{C}$ & 3638 & 1197 & 3020 & 17827 \\
\hline $140^{\circ} \mathrm{C}$ & 1907 & 1099 & 2254 & 11142 \\
\hline $150^{\circ} \mathrm{C}$ & 1747 & 750 & 1838 & 10233 \\
\hline $160^{\circ} \mathrm{C}$ & 1258 & 724 & 1635 & 7143 \\
\hline $170^{\circ} \mathrm{C}$ & 911 & 635 & 1307 & 5086 \\
\hline $180^{\circ} \mathrm{C}$ & 653 & 510 & 1126 & 3499 \\
\hline $190^{\circ} \mathrm{C}$ & 1907 & 1099 & 2254 & 11142 \\
\hline $200^{\circ} \mathrm{C}$ & 7814 & 1597 & 4922 & 30527 \\
\hline $210^{\circ} \mathrm{C}$ & 1907 & 1099 & 2254 & 11142 \\
\hline
\end{tabular}

\section{Conclusion}

Compounds N,N-Terephthalylidene-bis-4- butyl aniline [A] and $\mathrm{N}$-(4-[5-(4-alkoxy phenyl) -1,3,4-oxadiazol-2-yl) phenyl)-1-[4-(4-(5-(4-alkoxy phenyl)-1,3,4-oxadiazol-2-ylphenyl-imino-methyl phenyl methanimine $[5]_{\mathrm{d}}$ were prepared and characterized using techniques FTIR, 1HNMR, DSC and POM, as well as used as a stationary phase to separate polyaromatic hydrocarbons. The best separation among them was the compound $[\mathrm{A}]$ at $210^{\circ} \mathrm{C}$.

\section{References}

[1] Andrienko D.; "Introduction to liquid crystals". Journal of Molecular Liquids, 267, 520-541, 2018.

[2] Collings P. J. and Goodby J. W.; "Introduction to liquid crystals: chemistry and physics". Crc Press, 2019.

[3] Sharma P. and Raina K. K.; "Investigations on magnetic nanoparticle liquid crystal composites". Doctoral Dissertation, 2018.

[4] Grajek H.; Witkiewicz Z.; Purchała M. and Drzewiński W.; "Liquid Crystals as Stationary Phases in Chromatography". Chromatographia, 79(19), 12171245, 2016. https://doi.org/10.1007/s10337-016-31545.

[5] Ghanem, E. and Al-Hariri S.; "Separation of isomers on nematic liquid crystal stationary phases in gas chromatography: a review". Chromatographia, 77(910), 653-662, 2014.

[6] Jensen J.; Grundy S. C.; Bretz S. L. and Hartley C. S.; "Synthesis and characterization of self-assembled liquid crystals: P-alkoxybenzoic acids". Journal of Chemical Education, 88(8), 1133-1136, 2011.

[7] López-Herraiz M.; Castillo-Martínez E.; CarreteroGonzález J.; Carrasco J.; Rojo T. and Armand M.; "Oligomeric-Schiff bases as negative electrodes for sodium ion batteries: unveiling the nature of their active redox centers". Energy \& Environmental Science, 8(11), 3233-3241, 2015.

[8] Nida N. F.; Abdul-Rauf M.; Siddiqui A.; Al-Sheddi, E. S. and Al-Oqail M. M.; "A facile one-pot synthesis of novel 2,5-disubstituted-1,3,4-oxadiazoles under conventional and microwave conditions and evaluation of their in vitro antimicrobial activities". Arabian Journal of Chemistry, 10 (2), 2853-2860, 2017.

[9] Revanasiddappa B. C. and Subrahmanyam E. V. S.; "Synthesis of some 1, 3, 4-Oxadiazole derivatives as potential biological agents". Int. J. Chem. Sci.: 7(4), 2508-2512, 2009.

[10] Vhanale B. T.; Deshmukh N. J. and Shinde A. T.; "Synthesis, characterization, spectroscopic studies and biological evaluation of Schiff bases derived from 1hydroxy-2-acetonapthanone". Heliyon, 5(11), e02774, 2019.

[11] Munem M. A. Al-Haideri and Mehdawy M. Tur. J. Chem.; 27, 259, 2003.

[12] Benalia M.; Badjah-Hadj-Ahmed A. Y.; Djedid M.; Meklati B. Y.; Al-Dujaili A. H. and Ferkous F. A.; "Comparative analytical study of two new liquid crystals used as stationary phases in GC". Chromatographia, 66(7), 565-570, 2007.

[13] Ettre L. S.; "The nomenclature of chromatography: II. Liquid chromatography". Journal of Chromatography A, 220(1), 29-63, 1981. 